\title{
THE AMPLITUDES OF SEISMIC WAVES REFLECTED AND REFRACTED AT THE EARTH'S CORE*
}

\author{
By.Stephen W. Dana
}

THE PRESENT PAPER is based upon the author's recent investigation of "The Partition of Energy among Seismic Waves Reflected and Refracted at the Earth's Core." ${ }^{1}$ Its purpose is the expression of the amplitudes of certain waves reflected and refracted at the earth's core in terms of the horizontal and vertical components of the displacement which they produce at the surface of the earth.

The assumptions made before commencing the calculations were: first, a zero focal depth for the source of the seismic waves; second, that any discontinuities between the core and the surface of the earth have a negligible effect upon the passage of the body waves considered; and third, that no appreciable discontinuities exist within the core.

The amplitude $A$ of a seismic wave arriving at the surface of the earth is given by

$$
A=C T f \sqrt{e^{-\int k d D} \frac{\tan i_{0}}{\sin \Delta} \frac{d i_{0}}{d \Delta}} .
$$

All assumptions involved in the derivation of this equation ${ }^{2}$ apply here. The exponential term represents the absorption which has taken place along the path $D$ of the wave. Since the value of the absorption constant $k$ is not known accurately, and since the absorption probably does not differ much for the various waves under consideration, this term is taken as 1.00 in the following work. However, in comparing amplitudes of a given phase at various distances, the absorption term may produce noticeable effects.

Concerning the remaining symbols in equation (1):

$i_{0}=$ the angle of incidence of the wave at the earth's surface.

$\Delta=$ the angular distance from its source to its point of emergence.

$C=$ a constant, its value dependent upon the energy at the focus of the shock and different for $\mathrm{P}, \mathrm{SH}$, and $\mathrm{SV}$ waves. In the present calculations it was assumed equal to $\pi$.

$T=$ the period of the wave, taken as 1.00 second throughout these calculations. Therefore, in using the results of this paper, measured values of $T$ must be introduced according to equation (1).

$f=\sqrt{f_{1} f_{2} f_{3} \ldots}$, the values of $\sqrt{f_{1}}, \sqrt{f_{2}}, \sqrt{f_{3}}$, etc., representing the square root of the fraction of energy remaining after a reflection or refraction at the earth's core, calculated in Dana, ${ }^{3}$ or after a reflection at the surface of the earth.

$u, v$, and $w$ denote the three components of the ground displacement produced by a seismic wave at its point of emergence. $u$ is the horizontal component of the ground displacement in the plane of propagation, $v$ is the horizontal component perpendicular to the plane of propagation, and $w$ is the vertical component of the ground dis-

\footnotetext{
* Condensed from a thesis submitted in partial fulfillment of the requirements for the degree of Doctor of Philosophy at the California Institute of Technology, Pasadena, California. Manuscript received for publication June 29, 1944.

I Bull. Seism. Soc. Am., 34:189-197 (1944).

2 See B. Gutenberg, "Die Bahnen der Erdbebenwellen im Erdinnern," Handbuch der Geophysik, 4:32-80 (1929).

${ }^{3}$ S. W. Dana, "The Partition of Energy among Seismic Waves Reflected and Refracted at the Earth's Core," Bull. Seism. Soc. Am, 34:189-197 (1944).
} 
placement. All three are computed by multiplying $A$ with the ratios $u / A, v / A$, and $w / A$, respectively. These ratios are dependent for longitudinal waves only upon the angle of incidence and Poisson's Ratio in the surface layer of the earth, and for shear waves they are dependent, besides, upon the polarization.

For shear waves of the SH type $u / A$ and $w / A$ are zero, whereas $v / A$ is always 2.00. Values of $u / A$ and $w / A$ for an incident $\mathrm{P}$ wave and an incident $\mathrm{SV}$ wave for $i_{0}=0^{\circ}$ to $90^{\circ}$ may be found in a figure of Gutenberg's. ${ }^{4}$ This figure also contains a plot of the square root of the relative energy for waves reflected from the surface of the earth both for an incident $\mathrm{P}$ and an incident $\mathrm{SV}$ wave. These values were required for calculating the $f$ of body waves which had been reflected at least once from the earth's surface in the course of their path. All curves used in Gutenberg's figure were for $\sigma=0.239$.

The value of $i_{0}$ at a certain $\Delta$ was calculated from travel-time curves plotted from data contained in papers by Gutenberg and Richter, ${ }^{5}$ and by using

$$
\sin i_{0}=\frac{V_{0}}{\bar{V}_{\Delta}}
$$

where $V_{0}$ is the true velocity of a longitudinal or shear wave in the surface of the earth and $\bar{V}_{\Delta}$ is the apparent velocity $\left(\frac{d \Delta}{d t}\right)$ of that wave at a particular $\Delta . V_{0}$ was taken to be $5.5 \mathrm{~km}$. per sec. and $3.2 \mathrm{~km}$. per sec. for $\mathrm{P}$ and $\mathrm{S}$ waves, respectively (corresponding to the top of the "granitic layer" in the continents). The values of $i_{0}$ thus obtained were plotted against $\Delta$ for each seismic wave. The slope to this curve evaluated the differential $\frac{d i_{0}}{d \Delta}$. It may be pointed out that $f \sqrt{\frac{\tan i_{0}}{\sin \Delta} \frac{d i_{0}}{d \Delta}}$ is a pure number.

The value of the angle of incidence $i_{c}$ of a certain wave at the core of the earth is determined from the equation

$$
\frac{r_{0} \sin i_{0}}{V_{0}}=\frac{r_{c} \sin i_{c}}{V_{c}}
$$

$V_{0}$ is the velocity of the wave at the surface of the earth $(5.5$ or $3.2 \mathrm{~km}$. per sec.), and $V_{c}$ is the velocity of the wave in the mantle at the core (taken as in Dana to be $13.7 \mathrm{~km}$. per sec. for $\mathrm{P}$ waves and $7.25 \mathrm{~km}$. per sec. for $\mathrm{S}$ waves). $r_{c}$ is the radius of the core of the earth $\left(3,446 \mathrm{~km}\right.$.), and $r_{0}$ is the radius of the earth $\left(6,366 \mathrm{~km}\right.$.). It is $i_{c}$ which determines the value of $f$ for a given wave from the plots of square root of relative energy against angle of incidence in Dana. In the case of a wave transmitted by the core of the earth, the angle of incidence at which it enters the core is determined by Snell's Law, using $8.00 \mathrm{~km}$. per sec. for the velocity of $\mathrm{P}$ waves just inside the core (again see Dana). ${ }^{6}$

4 B. Gutenberg, "Energy Ratio of Reflected and Refracted Seismic Waves," Bull. Seism. Soc. Am., 34:85-102 (1944), p. 99, fig. 3.

5 B. Gutenberg and C. F. Richter, "On Seismic Waves (First Paper)," Gerland's Beiträge aur Geophysik, 43:56-133 (1934); "On Seismic Waves (Second Paper)," ibid., 45:280-360 (1935); "P' and the Earth's Core," Mon. Not. Roy. Astron. Soc., Geophys. Suppl., 4:363-372 (1938);"On Seismic Waves (Fourth Paper)," Gerlands Beiträge z. Geophysiz, 54:94-136 (1939).

${ }^{6}$ References to Dana in this paragraph are to the paper cited in notes 1 and 3 . 
In the following work, the horizontal and vertical components, $u$ and $w$, of the surface displacement produced by seismic waves were calculated first for $\mathrm{P}, \mathrm{SV}$, PP, and SS (SV type), and are given in table 1.

It will be noted that certain values of $u$ and $w$ are given as infinity. This is merely a mathematical statement because at certain points $\left(\dot{\Delta}=0^{\circ}\right.$ or $\left.180^{\circ}\right)$ sin $\Delta$ in the amplitude equation becomes zero. Also in the plots of $i_{0}$ vs. $\Delta$ for waves transmitted by the core at their focal points $d i_{0} / d \Delta$ becomes infinity. Either of these two factors

\section{TABLE 1}

Calculated Values of $u$ (Horizontal Displacement) and $w$ (Vertical Displacement) for $\mathrm{P}, \mathrm{SV}, \mathrm{PP}$, and SS (SV Type) as a Function of the Distance $\Delta$, Assuming $C=\pi$ And $T=1.00$ Sec. in Equation (1) and Neglecting Absorption

\begin{tabular}{|c|c|c|c|c|c|c|c|c|}
\hline \multirow{2}{*}{$\Delta$} & \multicolumn{2}{|c|}{$\mathrm{P}$} & \multicolumn{2}{|c|}{ sV } & \multicolumn{2}{|c|}{$\mathrm{PP}$} & \multicolumn{2}{|c|}{ SS (SV type) } \\
\hline & $u$ & $w$ & $u$ & $w$ & $u$ & $w$ & $u$ & $w$ \\
\hline $\begin{array}{c}\text { deg. } \\
15\end{array}$ & 8.57 & 9.73 & 3.59 & 9.67 & $\ldots$ & $\ldots$ & $\ldots$ & $\ldots$ \\
\hline 19 & 5.40 & 7.35 & 26.35 & 2.535 & $\ldots$ & $\ldots$ & $\ldots$ & $\ldots$ \\
\hline 20 & 4.89 & 6.64 & 14.49 & .000 & $\ldots$ & $\ldots$ & $\ldots$ & $\ldots$ \\
\hline 30 & 1.71 & 3.15 & 3.435 & 1.959 & 1.70 & 1.928 & 1.822 & 4.91 \\
\hline 38 & $\ldots$ & $\ldots$ & $\ldots$ & $\ldots$ & $\ldots$ & $\ldots$ & 4.19 & 0.403 \\
\hline 40 & 1. 108 & 2.22 & 2.025 & 1.084 & 1.362 & 1.851 & 0.000 & .000 \\
\hline 44.4 & $\ldots$ & $\ldots$ & $\ldots$ & $\ldots$ & $\ldots$ & $\ldots$ & .372 & .255 \\
\hline 50 & 0.885 & 1.894 & 1.761 & 0.917 & .0974 & 1.530 & .0724 & .0556 \\
\hline 52.6 & $\ldots$ & $\ldots$ & $\ldots$ & $\ldots$ & $\ldots$ & $\ldots$ & .000 & .000 \\
\hline 60 & .724 & 1.717 & 1.575 & .717 & .644 & 1.188 & .2055 & .1172 \\
\hline 70 & .524 & 1.531 & 1.388 & .568 & .489 & 0.941 & .224 & .1231 \\
\hline 80 & .458 & 1.435 & 1.155 & .449 & .470 & .940 & .2897 & .1544 \\
\hline 90 & .389 & 1.295 & 1.061 & .392 & .452 & .936 & .312 & .1644 \\
\hline 100 & .2185 & 0.849 & 0.991 & .319 & .436 & .934 & .3303 & .1719 \\
\hline 101 & .190 & 0.740 & 0.970 & 0.3055 & $\ldots$ & $\ldots$ & $\ldots$ & $\ldots$ \\
\hline 103 & 0.1071 & 0.416 & $\ldots$ & $\ldots$ & $\ldots$ & $\therefore$ & $\ldots$ & $\ldots$ \\
\hline 110 & & & & & .424 & .955 & .405 & .1970 \\
\hline 120 & Not & Not & Not & Not & .414 & 0.984 & .447 & .203 \\
\hline 140 & existent & existent & existent & existent & .392 & 1.147 & .604 & .2464 \\
\hline 160 & & & & & 0.488 & 1.528 & 0.791 & 0.3078 \\
\hline 180 & & & & & $\infty$ & $\infty$ & $\infty$ & $\infty$ \\
\hline
\end{tabular}

gives a value of infinity to the amplitude of a seismic wave. However, in the physical sense this merely means that the value of the amplitude becomes much greater than the amplitudes at neighboring distances on that particular plot. At focal points of waves transmitted by the core, for example, actual measurements show that the amplitudes become as much as twenty times the value of amplitudes at distances on both sides of the focal points.

Next, $u$ and $w$ were calculated for the group of waves reflected once from the surface of the core. They are given in table 2.

The values of $w$ for PcP and of $u$ for ScS (SV type) at $\dot{\Delta}=0^{\circ}$ were approximated by replacing $\frac{\tan i_{0}}{\sin \Delta}$ with $i_{0} / \Delta$, where $i_{0}$ and $\Delta$ are in radians. In the vicinity of $\Delta=0^{\circ}$ for this group of waves ( $\mathrm{PcP}, \mathrm{PcS}, \mathrm{ScS}$, and $\mathrm{ScP})$ the slope of the $i_{0}$ vs. $\Delta$ curve is 
a constant. Since $i_{0}=0^{\circ}$ at $\Delta=0^{\circ}$, integration of $d i_{0} / d \Delta$ shows that $d i_{0} / d \Delta=i_{0} / \Delta$ $=K$. Thus $\sqrt{\frac{\tan i_{0}}{\sin \Delta} \frac{d i_{0}}{d \Delta}}=K$ in the vicinity of $\Delta=0^{\circ}$, where $K$ is the slope of the $i_{0}$ vs. $\Delta$ curve. The values $u=w=0$ at $\Delta=94^{\circ} .5$ for PcP are due to the critical angle of incidence at the core, at which $f$ for PcP is zero. The maximum in $u$ and $w$ for $\operatorname{SeS}$ (SV type) at $\Delta=28^{\circ}$ is caused by the total reflection of energy $(f=1.00)$ from the core of the earth at this particular $\Delta$.

\section{TABLE 2}

Calculated Values of $u$ and $w$ for PeP, PeS, SeS (SH and SV Trpes), and ScP (Assumptions are the same as in table 1)

\begin{tabular}{|c|c|c|c|c|c|c|c|c|c|}
\hline \multirow{2}{*}{$\Delta$} & \multicolumn{2}{|c|}{$\mathrm{PcP}$} & \multicolumn{2}{|c|}{ PoS } & \multicolumn{2}{|c|}{$\begin{array}{c}\operatorname{SeS} \\
\text { (SV type) }\end{array}$} & \multirow{2}{*}{$\begin{array}{c}\begin{array}{c}\mathrm{SeS} \\
\text { (SH type) }\end{array} \\
v\end{array}$} & \multicolumn{2}{|c|}{$\mathrm{ScP}$ : } \\
\hline & $u$ & $w$ & $u$ & $w$ & $u$ & $w$ & & $u$ & $w$ \\
\hline $\begin{array}{c}\text { deg. } \\
0\end{array}$ & 0.000 & 0.0744 & 0.000 & 0.000 & 1.798 & 0.000 & 1.798 & 0.000 & 0.000 \\
\hline 10 & .008 & .126 & .240 & .010 & 1.615 & .090 & 1.752 & .027 & .380 \\
\hline 20 & .021 & .235 & .372 & .029 & 1.165 & .125 & 1.700 & .091 & .654 \\
\hline 28 & $\ldots \ldots$ & $\ldots$ & $\ldots$ & $\ldots$ & 1. 459 & .2045 & $\ldots$ & $\ldots \ldots$ & $\ldots \ldots$ \\
\hline 30 & .049 & .329 & .383 & .042 & 0.640 & .116 & 1. 445 & .125 & .701 \\
\hline 40 & .072 & .399 & .313 & .040 & .520 & .095 & $1.31 \mathrm{~J}$ & .117 & .572 \\
\hline 50 & .079 & .397 & .233 & .0315 & .525 & .125 & 1.160 & .105 & .392 \\
\hline 60 & .0775 & .305 & .212 & .030 & .630 & .170 & 0.970 & .041 & .215 \\
\hline 652 & $\ldots$ & $\ldots$ & 0.000 & 0.000 & $\ldots \ldots$ & $\ldots$ & $\ldots$ & $\ldots \ldots$ & $\ldots$ \\
\hline 65.4 & $\ldots$ & $\ldots$ & & & .803 & .219 & $\ldots$. & $\ldots \ldots$ & $\ldots \ldots$ \\
\hline 65.5 & $\ldots \ldots$ & $\ldots \ldots$ & & & $\ldots \ldots$ & $\ldots \ldots$ & $\ldots$ & 0.000 & 0.000 \\
\hline 70 & .0535 & .206 & & & .690 & .200 & .738 & & \\
\hline 80 & .029 & .143 & Not. & Not & .557 & .160 & .590 & Not & Not \\
\hline 90 & .016 & .053 & existent & existent & .452 & .140 & .485 & existent & existent \\
\hline 94.5 & .000 & .000 & & & $\ldots \ldots$ & $\ldots \ldots$ & $\ldots$ & & \\
\hline 100 & .034 & .102 & & & .375 & .115 & .405 & & \\
\hline 101 & .042 & .128 & & & 0.370 & 0.110 & 0.395 & & \\
\hline 103 & 0.058 & .212 & & & $\begin{array}{c}\text { Not } \\
\text { existent }\end{array}$ & $\begin{array}{c}\text { Not } \\
\text { existent }\end{array}$ & $\begin{array}{l}\text { Not } \\
\text { existent }\end{array}$ & & \\
\hline
\end{tabular}

Table 3 gives the ratios of the $u$ and $w$ of the waves in table 2 to the $u$ and $w$ of $\mathrm{P}$ or SV. The components of $\mathrm{P}$ were used if the wave started from its source as longitudinal ( $\mathrm{PcP}$ and $\mathrm{PcS}$ ), and the components of $\mathrm{SV}$ were used if the wave started from its source as a shear wave ( $\mathrm{ScS}$ and $\mathrm{ScP}$ ). This was done on account of the fact, mentioned earlier, that the value of the constant $C$ in the amplitude equation depends upon the energy at the source of the shock and has the same value for all waves starting as $\mathrm{P}$ and another value for all waves starting as $\mathrm{SV}$ waves. Thus the necessity of the determination of $C$ is avoided, since $\mathrm{PcP}$, for example, has the same $C$ as the wave $\mathrm{P}$, and in the ratio of the $u$ of $\mathrm{PcP}$ to the $u$ of $\mathrm{P}$ the $C$ cancels out. It should be noted that in general the $u$ and $w$ values were determined only for distance intervals of $10^{\circ}$. This takes no account of minor irregularities in the traveltime curves. In addition, it should be noted that all results of amplitude ratios in this paper must be multiplied by the ratio of the periods $T$ of the respective waves to find values comparable with observations from seismograms, and that the ratio 
of trace amplitudes in seismograms to the ground movement discussed in this paper depends upon the period $T$. Also, where the ratios of SH type to SV type waves are used, the ratio of the corresponding values of $C$ must be considered before comparing observations from seismograms with the calculated values.

The next step in these calculations was the determination of $u$ and $w$ for seismic waves transmitted once by the core of the earth. This group consists of $\mathrm{P}^{\prime}(=\mathrm{PKP})$, PKS, SKS, and SKP. The travel-time curve for each one of these four waves con-

TABLE 3

Calculated Values of $u$ and $w$ Ratios for PeP to P, PeS to P, SeS (SV) to SV, SeS (SH) to $\mathrm{SV}, \mathrm{ScS}(\mathrm{SH})$ to SH, AND ScP to SV

(Assumptions are the same as in table 1)

\begin{tabular}{|c|c|c|c|c|c|c|c|c|c|c|}
\hline \multirow{2}{*}{$\Delta$} & \multicolumn{2}{|c|}{$\mathrm{PcP} / \mathrm{P}$} & \multicolumn{2}{|c|}{$\mathrm{PcS} / \mathrm{P}$} & \multicolumn{2}{|c|}{$\mathrm{SeS}(\mathrm{SV}) / \mathrm{SV}$} & \multirow{2}{*}{$\frac{\substack{\mathrm{SoS}(\mathrm{SH}) \\
/ \mathrm{SV}}}{v / u}$} & \multirow{2}{*}{$\begin{array}{c}\mathrm{SeS}(\mathrm{SH}) \\
/ \mathrm{SH} \\
v\end{array}$} & \multicolumn{2}{|c|}{$\mathrm{ScP} / \mathrm{SV}$} \\
\hline & $u$ & $w$ & $u$ & $w$ & $u$ & $w$ & & & $u$ & $w$ \\
\hline $\begin{array}{l}\text { deg. } \\
15\end{array}$ & 0.0015 & 0.0175 & 0.0369 & 0.0018 & 0.398 & 00126 & 0.403 & 00956 & 00164 & 00565 \\
\hline 20 & .0038 & .0302 & .0673 & .0041 & .081 & $\infty$ & .1124 & .1792 & .0062 & $\infty$ \\
\hline 28 & $\ldots$ & $\ldots \ldots$ & $\ldots \ldots$ & $\ldots \ldots$ & .3745 & .1079 & $\ldots \ldots$ & $\ldots \ldots$ & $\ldots \ldots$ & $\ldots \ldots$ \\
\hline 30 & .0270 & .1022 & .2152 & .0132 & .357 & .0869 & .421 & .3579 & .0362 & .3578 \\
\hline 40 & .0675 & .1855 & .3139 & .0199 & .2578 & .0875 & .648 & .5573 & .0573 & .526 \\
\hline 50 & .0917 & .2082 & .2653 & .0175 & .2978 & .134 & .659 & .5753 & .0590 & 425 \\
\hline 60 & .1130 & .2024 & .2395 & .1043 & .3998 & .2375 & .615 & .5474 & .0286 & .300 \\
\hline 64.2 & $\ldots \ldots$ & $\ldots \ldots$ & 0.0000 & 0.0000 & $\therefore \ldots$ & $\ldots \ldots$ & $\ldots \ldots$ & & $\ldots \ldots$ & $\ldots \ldots$ \\
\hline 65.4 & & $\ldots \ldots$ & & & .540 & .339 & & & & $\ldots$ \\
\hline 65.5 & $\ldots \ldots$ & $\ldots \ldots$ & & $\ldots \ldots$ & $\therefore \ldots$ & $\ldots \ldots$ & $\ldots \ldots$ & $\therefore \ldots$ & 0.0000 & 0.0000 \\
\hline 70 & .1249 & .1741 & & & .500 & .350 & .533 & .4824 & & \\
\hline 80 & .0985 & .1263 & & & .480 & '. 356 & .504 & .4586 & & \\
\hline 90 & .0388 & .0437 & & & .424 & .357 & .458 & .4214 & & \\
\hline 94.5 & .0000 & .0000 & & & & $\ldots$ & & 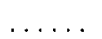 & & \\
\hline 100 & .1416 & .1379 & & & .3785 & .3605 & .406 & .3776 & & \\
\hline 101 & $\ldots \ldots$ & $\ldots \ldots$ & $\ldots \ldots$ & $\ldots \ldots$ & 0.381 & 0.3635 & 0.407 & 0.3805 & & \\
\hline 103 & 0.3319 & 0.3117 & $\ldots \ldots$ & & & $\ldots \ldots$ & & & & \\
\hline
\end{tabular}

tains four branches (except SKS, which has three) with three reversals of direction (focal points). In general, the range covered is from just beyond $\Delta=100^{\circ}$ to $\Delta=180^{\circ}$. Only some of the important points will be described for this group of waves.

$u$ and $w$ for $\mathrm{P}^{\prime}$ start out at infinity at $\Delta=180^{\circ}$, have a minimum near $\Delta=155^{\circ}$ (where $u=0.1218$ and $w=0.465$ ), and then increase to infinity again at $\Delta=1421 / 2^{\circ}$ focal point). From there $u$ and $w$ decrease to about 0.071 for $u$ and 0.350 for $w$ in the range from $\Delta=145^{\circ}$ to $165^{\circ}$ and then increase to infinity at the focal point $\Delta=169^{\circ}$. Going from that point back to $\Delta=110^{\circ}$ on the next branch, $u$ decreases steadily to 0.0258 and $w$ to 0.1865 at $\Delta=120^{\circ}$, and both increase to infinity at the third focal point $\Delta=110^{\circ}$. For the fourth branch of $\mathrm{P}^{\prime}$ (from $\Delta=110$ to $180^{\circ}$ ) $u$ decreases to 0.0253 at $\Delta=115^{\circ}$, increases to 0.0956 at $\Delta=160^{\circ}$, and then decreases to zero at $\Delta=180^{\circ}$. In this same range $w$ is 0.182 at $\Delta=115^{\circ}, 1.262$ at $\Delta=165^{\circ}$, and 0.417 at $\Delta=180^{\circ}$. 
Of the two waves PKS and SKP, which are very similar, only SKP will be described because its components are the larger. $u$ and $w$ for SKP are zero at $\Delta=1491 / 2^{\circ}$ and increase to infinity at the focal point $\Delta=131 / 2{ }^{\circ}(w$ staying just larger than $u$ in this range). $u$ then decreases to 0.0410 on the average from the range $\Delta=135^{\circ}$ to $155^{\circ}$ and becomes infinity at the next focal point $\left(\Delta=15834^{\circ}\right)$, while $w$ is about 0.220 for the same range and also infinity at $\Delta=15834^{\circ}$. From this point $u$ and $w$ decrease on the next branch back to $\Delta=110^{\circ}$, where $u=0.00772$ and $w=0.0589$, and become infinity at the third focal point $\left(\Delta=1041 / 4^{\circ}\right)$. For the fourth branch of SKP (from $\Delta=1041 /{ }^{\circ}$ to $180^{\circ}$ ) $u$ decreases to 0.00464 and $w$ to 0.0368 at $\Delta=110^{\circ}$, increases to 0.02293 ( $w$ to 0.2682 ) at $\Delta=155^{\circ}$, and becomes zero at $\Delta=180^{\circ}$ along with $w$.

TABLE 4

Calculated Values of $u$ and $w$ Ratios for $\mathrm{P}^{\prime}$ to PP, SKS to SS (SV), and SKP to SS (SV), Assuming Equal Periods and Neglecting Differences in Absorption

\begin{tabular}{|c|c|c|c|c|c|c|c|c|}
\hline \multicolumn{3}{|c|}{$\mathrm{P}^{\prime} / \mathrm{PP}$} & \multicolumn{3}{|c|}{ SKP/SS (SV) } & \multicolumn{3}{|c|}{ SKS/SS (SV) } \\
\hline$\Delta$ & $u$ & $w$ & $\Delta$ & $u$ & $w$ & $\Delta$ & $u$ & $w$ \\
\hline $\begin{array}{l}\text { deg. } \\
180\end{array}$ & 0.1638 & 0.1747 & $\begin{array}{l}\text { deg. } \\
1491 / 2\end{array}$ & 0.000 & 0.000 & $\begin{array}{c}\text { deg. } \\
80\end{array}$ & 2.39 & 1.141 \\
\hline 155 & .300 & .375 & $* 1311 / 2$ & $\infty$ & $\infty$ & 109 & 1.910 & 0.620 \\
\hline$* 1421 / 2$ & $\infty$ & $\infty$ & $135-155$ & .0690 & .890 & $109^{\circ} 42^{\prime}$ & 0.000 & .000 \\
\hline $145-165$ & .150 & .260 & $* 1583 / 4$ & $\infty$ & $\infty$ & 120 & .541 & .1497 \\
\hline *169 & $\infty$ & $\infty$ & 110 & .01903 & .2982 & 130 & .406 & .0990 \\
\hline 120 & .0624 & .1899 & $* 1041 / 4$ & $\infty$ & $\infty$ & & $\ldots$ & $\ldots \ldots \ldots$ \\
\hline$* 110$ & $\infty$ & $\infty$ & 110 & .01144 & .1868 & (Second & & \\
\hline 115 & .122 & .329 & 155 & .0220 & .690 & branch) & & \\
\hline 160 & .1958 & .736 & 180 & 0.000 & 0.000 & 135 & .072 & .010 \\
\hline 180 & 0.000 & 0.000 & $\ldots$ & $\ldots \ldots$ & $\ldots \ldots$ & 140 & .041 & .0075 \\
\hline$\ldots$ & $\ldots \ldots$ & $\ldots \ldots$ & $\ldots$ & & & 150 & 0.0374 & 0.0062 \\
\hline
\end{tabular}

* Focal points.

The remaining wave of this group, SKS, was studied only in the range of $\Delta$ between $80^{\circ}$ and $150^{\circ}$. For SKS $u$ is 0.693 and $w$ is 0.1765 at $\Delta=80^{\circ}$. They decrease slowly to $\Delta=109^{\circ}$, where $u=0.1695$ and $w=0.0266$. Then at $\Delta=109^{\circ} 42^{\prime}$ both become zero, owing to the critical angle of incidence at the inner surface of the core when all the energy is reflected back into the core. Beyond $\Delta=109^{\circ} 42^{\prime}$, $u$ increases to 0.242 at $\Delta=120^{\circ}(w=0.0304$ here $)$ and then decreases to 0.207 at $\Delta=130^{\circ}$, where $w=0.0218$. From $\Delta=135^{\circ}$ to $150^{\circ}$ another branch of SKS was considered in these calculations. For this branch $u$ is 0.0529 and $w$ is 0.00424 at $\Delta=135^{\circ}$, and both decrease to $\Delta=150^{\circ}$ (where $u=0.0250$ and $w=0.00163$ ).

Since the range of $\mathrm{P}^{\prime}$, SKP, and SKS is beyond that of $\mathrm{P}$ or $\mathrm{SV}$, the $u$ and $w$ ratios calculated using them were made with PP and SS (SV type). In this case PP was used if the wave started from its source as longitudinal, and SS (SV) was used if the wave started as shear. Thus the value of $C$ in the amplitude equation cancels out. These ratios are given in table 4 for the $\Delta$ values mentioned in the description of the waves transmitted once by the core of the earth.

The ground displacements $u$ and $w$ due to the group of waves reflected once from 
the interior surface of the core (PKKP, PKKS, SKKS, and SKKP) were calculated only for certain of their branches. $u$ and $w$ for PKKP are $\infty$ at $\Delta=120^{\circ}$ (a focal point) and then decrease steadily to $\Delta=95^{\circ}$, where $u$ is 0.00479 and $w$ is 0.0256 . The travel-time curve for SKKP and PKKS is the same, but since the components of SKKP are the larger they will be given. $u$ is 0.0149 and $w$ is 0.0619 for SKKP at $\Delta=132^{\circ}$. These decrease to $\Delta=100^{\circ}$, at which point $u=0.001309$ and $w=0.00708$. The $u$ of SKKS is 0.317 at $\Delta=100^{\circ}$, and the $w$ is 0.0776 . They decrease to 0.1322 for $u$ and 0.0305 for $w$ at $\Delta=115^{\circ}$, increase to a maximum of 0.367 for $u$ and 0.0735 for $w$ at $\Delta=150^{\circ}$, and decrease to $\Delta=165^{\circ}$, where $u$ is 0.2708 and $w$ is 0.0518 . The large values of the horizontal component of SKKS show that it is the strongest of this group of waves for the $\Delta$ range studied.

TABLE 5

Calculated Values of $u$ and $w$ Ratios for PKKP to PP, SKKS to SS(SV), AND SKKP To SS(SV)

(Assumptions are the same as in table 4 )

\begin{tabular}{c|c|c|c|c|c|c|c|c}
\hline \hline \multicolumn{3}{|c|}{ PKKP/PP } & \multicolumn{3}{c|}{ SKKS/SS (SV) } & \multicolumn{3}{c}{ SKKP/SS (SV) } \\
\hline$\Delta$ & $u$ & $w$ & $\Delta$ & $u$ & $w$ & $\Delta$ & $u$ & $w$ \\
\hline deg. & & & deg. & & & deg. & & \\
120 & $\infty$ & $\infty$ & 100 & 0.961 & 0.451 & 132 & 0.02782 & 0.2745 \\
115 & 0.0362 & 0.0740 & 115 & .318 & .156 & 130 & .02619 & .2642 \\
110 & .02155 & .0484 & 130 & .303 & .1557 & 120 & .01072 & .1211 \\
105 & .01258 & .03015 & 140 & .364 & .1929 & 115 & .0070 & .0725 \\
100 & .01161 & .02865 & 150 & .550 & .2781 & 110 & .00501 & .0543 \\
95 & 0.01075 & 0.02735 & 165 & 0.300 & 0.1451 & 100 & 0.00396 & 0.0412 \\
\hline
\end{tabular}

Table 5 gives the $u$ and $w$ ratios calculated for the waves reflected once from the interior surface of the core for the $\Delta$ values listed in their description.

The last groups of waves for which $u$ and $w$ were calculated were $\mathrm{P}^{\prime} \mathrm{P}^{\prime}$ and $\mathrm{P}^{\prime} \mathrm{P}^{\prime} \mathrm{P}^{\prime}$. The form of the $u$ and $w$ curves when plotted against $\Delta$ is similar to the form of the same type of curve for $\mathrm{P}^{\prime}$; that is, there are four branches with three reversals of direction (focal points).

$u$ and $w$ for $\mathrm{P}^{\prime} \mathrm{P}^{\prime}$ start at infinity at $\Delta=0^{\circ}$, decrease to 0.0423 for $u$ and 0.1595 for $w$ at $\Delta=40^{\circ}$, and increase to infinity at the focal point $\Delta=75^{\circ}$. (corresponds to $\Delta=1421 / 2$ for $\mathrm{P}^{\prime}$ ). Then $u$ decreases to 0.0260 for the range $\Delta=70^{\circ}$ to $25^{\circ}$, in which $w$ is about 0.130 , and they both increase to infinity at the focal point $\Delta=22^{\circ}$ (corresponds to $\Delta=169^{\circ}$ for $\mathrm{P}^{\prime}$ ). $u$ decreases steadily from this focal point to 0.01473 at $\Delta=100^{\circ}$, and increases again to infinity at the third focal point $\Delta=140^{\circ}$ (corresponds to $\Delta=110^{\circ}$ for $\mathrm{P}^{\prime}$ ). $w$ does the same in this range for $\mathrm{P}^{\prime} \mathrm{P}^{\prime}$ except that it is 0.1045 at $\Delta=100^{\circ}$. In the fourth branch of $\mathrm{P}^{\prime} \mathrm{P}^{\prime}$ from $\Delta=140^{\circ}$ to $0^{\circ}$, $u$ and $w$ decrease from infinity to 0.0246 for $u$ and 0.1778 for $w$ at $\Delta=120^{\circ}$, increase to 0.0466 for $u$ and 0.546 for $w$ at $\Delta=40^{\circ}$ (corresponds to the maximum in $\mathrm{P}^{\prime}$ at $\Delta=160^{\circ}$ ), and decrease to 0.000 for $u$ and 0.208 for $w$ at $\Delta=0^{\circ}$.

In the case of $\mathrm{P}^{\prime} \mathrm{P}^{\prime} \mathrm{P}^{\prime}, u$ and $w$ start at infinity at $\Delta=180^{\circ}$, decrease to $u=0.0175$ and $w=0.0661$ at $\Delta=120^{\circ}$, and increase to infinity at the focal point $\Delta=67.5^{\circ}$ $\left(\Delta=1421 / 2\right.$ for $\left.\mathrm{P}^{\prime}\right) . u$ then decreases to about 0.013 in the range $\Delta=70^{\circ}$ to $140^{\circ}$ 
( $w$ becomes 0.0690 ) and becomes infinity along with $w$ at the second focal point $\Delta=147^{\circ}$ (corresponding to $\Delta=169^{\circ}$ for $\mathrm{P}^{\prime}$ ). $u$ and $w$ decrease to 0.0141 for $u$ and 0.100 for $w$ at $\Delta=60^{\circ}$ and become infinity at the third focal point $\Delta=-30^{\circ}$ $\left(\Delta=110^{\circ}\right.$ for $\left.\mathrm{P}^{\prime}\right)$. In the fourth branch of $\mathrm{P}^{\prime} \mathrm{P}^{\prime} \mathrm{P}^{\prime}$ (from $\Delta=-30^{\circ}$ to $180^{\circ}$ ) $u$ decreases to 0.01372 and $w$ to 0.140 at $\Delta=90^{\circ}$, then $u$ increases to 0.0308 and $w$ to 0.362 at $\Delta=120^{\circ}$, and finally $u$ decreases to 0.000 and $w$ to 0.1388 at $\Delta=180^{\circ}$. It should be mentioned that the values of components calculated at $\Delta=180^{\circ}$ or $0^{\circ}$ for $\mathrm{P}^{\prime}, \mathrm{P}^{\prime} \mathrm{P}^{\prime}$, and $\mathrm{P}^{\prime} \mathrm{P}^{\prime} \mathrm{P}^{\prime}$ were approximated by plotting $\frac{\tan i_{0}}{\sin \Delta}$ as $\Delta$ increased from $170^{\circ}$ to within a few minutes of $180^{\circ}$. Although $i_{0}$ is also very small for these waves in

TABLE 6

Calculated Values of $u$ and $w$ Ratios for $\mathrm{P}^{\prime} \mathrm{P}^{\prime}$ to $\mathrm{P}, \mathrm{P}^{\prime} \mathrm{P} / \mathrm{P}^{\prime}$ to $\mathrm{P}$, $\mathrm{P}^{\prime} \mathrm{P}^{\prime}$ to $\mathrm{PP}, \mathrm{AND} \mathrm{P}^{\prime} \mathrm{P}^{\prime} \mathrm{P}^{\prime}$ to $\mathrm{PP}$

(Assumptions are the same as in table 4)

\begin{tabular}{|c|c|c|c|c|c|c|c|c|c|}
\hline \multirow[b]{2}{*}{$\Delta$} & \multicolumn{2}{|c|}{$P^{\prime} P^{\prime} / P$} & \multicolumn{2}{|c|}{$\mathrm{P}^{\prime} \mathrm{P}^{\prime} / \mathrm{PP}$} & \multirow[b]{2}{*}{$\Delta$} & \multicolumn{2}{|c|}{$\mathrm{P}^{\prime} \mathrm{P}^{\prime} \mathrm{P}^{\prime} / \mathrm{P}$} & \multicolumn{2}{|c|}{$\mathrm{P}^{\prime} \mathrm{P}^{\prime} \mathrm{P}^{\prime} / \mathrm{PP}$} \\
\hline & $u$ & $w$ & $u$ & $w$ & & $u$ & $w$ & $u$ & $u$ \\
\hline $\begin{array}{r}\text { deg. } \\
40\end{array}$ & 0.0382 & 0.0720 & 0.0311 & 0.0861 & $\begin{array}{l}\text { deg. } \\
180\end{array}$ & Not exis & tent for & 0.0072 & 0.00789 \\
\hline$* 75$ & $\infty$ & $\infty$ & $\infty$ & $\infty$ & 120 & P beyond & $\Delta=103^{\circ}$ & 0.0423 & 0.0672 \\
\hline $70-25$ & 0.0310 & 0.0710 & $\begin{array}{c}0.030 \\
\text { (For } \Delta=\end{array}$ & $\begin{array}{c}0.093 \\
\left.70^{\circ}-30^{\circ}\right)\end{array}$ & $\begin{array}{r}* 67.5 \\
70-140\end{array}$ & $\begin{array}{c}\infty \\
0.078\end{array}$ & $\begin{array}{c}\infty \\
0.112\end{array}$ & $\begin{array}{c}\infty \\
0.0316\end{array}$ & $\begin{array}{c}\infty \\
0.0745\end{array}$ \\
\hline$* 22$ & $\infty$ & $\infty$ & $\begin{array}{r}\text { Not calc } \\
\text { for }\end{array}$ & $\begin{array}{l}\text { ulated } \\
\text { PP }\end{array}$ & $* 147$ & $\begin{array}{l}\text { (For } \Delta= \\
\text { Not exis }\end{array}$ & $\begin{array}{l}\left.70^{\circ}-103^{\circ}\right) \\
\operatorname{tent} \text { for }\end{array}$ & $\infty$ & $\infty$ \\
\hline 100 & 0.0674 & 0.1232 & 0.0338 & 0.112 & & $\mathbf{P}$ & & & \\
\hline$* 140$ & $\begin{array}{r}\text { Not exis } \\
\text { for }\end{array}$ & $\begin{array}{l}\text { tent } \\
\mathrm{P}\end{array}$ & $\infty$ & $\infty$ & $\begin{array}{r}60 \\
*-30\end{array}$ & $\begin{array}{c}0.0267 \\
\infty\end{array}$ & $\begin{array}{c}0.0799 \\
\infty\end{array}$ & $\begin{array}{c}0.03003 \\
\infty\end{array}$ & $\underset{\infty}{0.1151}$ \\
\hline 120 & beyond & $\Delta=103^{\circ}$ & 0.0595 & 0.1805 & 90 & 0.0353 & 0.1081 & 0.0304 & 0,1496 \\
\hline 40 & 0.0421 & 0.246 & 0.0342 & .2945 & $\begin{array}{l}120 \\
180\end{array}$ & $\begin{array}{r}\text { Not exi } \\
\text { for }\end{array}$ & stent & $\begin{array}{l}0.0746 \\
0.000\end{array}$ & $\begin{array}{l}0.368 \\
0.000\end{array}$ \\
\hline
\end{tabular}

* Focal points.

this vicinity, it was found that the ratio $\frac{\tan i_{0}}{\sin \Delta}$ approached a constant value and could be used in the amplitude equation.

$u$ and $w$ ratios for $\mathrm{P}^{\prime} \mathrm{P}^{\prime}$ to $\mathrm{P}, \mathrm{P}^{\prime} \mathrm{P}^{\prime} \mathrm{P}^{\prime}$ to $\mathrm{P}, \mathrm{P}^{\prime} \mathrm{P}^{\prime}$ to $\mathrm{PP}$, and $\mathrm{P}^{\prime} \mathrm{P}^{\prime} \mathrm{P}^{\prime}$ to $\mathrm{PP}$ were calculated for certain $\Delta$ ranges of $\mathrm{P}^{\prime} \mathrm{P}^{\prime}$ and $\mathrm{P}^{\prime} \mathrm{P}^{\prime} \mathrm{P}^{\prime}$. These are given in table 6 and are listed as far as possible for the $\Delta$ values mentioned in the description of $\mathrm{P}^{\prime} \mathrm{P}^{\prime}$ and $\mathrm{P}^{\prime} \mathrm{P}^{\prime} \mathrm{P}^{\prime}$. In cases where the amplitudes of $\mathrm{P}^{\prime} \mathrm{P}^{\prime}, \mathrm{P}^{\prime} \mathrm{P}^{\prime} \mathrm{P}^{\prime}$, and $\mathrm{PP}$ are infinity because $\Delta=180^{\circ}, \sqrt{\sin \Delta}$ cancels out in the amplitude ratios. For example, at $\Delta=180^{\circ}$ at the start of $\mathrm{P}^{\prime} \mathrm{P}^{\prime} \mathrm{P}^{\prime}, u=\frac{0.001778}{\sqrt{\sin 180^{\circ}}}$. For this same $\Delta, u$ for $\mathrm{PP}$ is $\frac{0.247}{\sqrt{\sin 180^{\circ}}}$. The $u$ ratio of $\frac{\mathrm{P}^{\prime} \mathrm{P}^{\prime} \mathrm{P}^{\prime}}{\mathrm{PP}}$ therefore becomes 0.00720 , as may be seen in table 6 .

No attempt has been made as yet to compare the calculated ratios of horizontal and vertical components of the ground displacement produced at the earth's surface 
by certain seismic waves with actual measurements from recorded earthquakes (considering the difference in periods of certain waves as has been pointed out). It is hoped that comparison of the calculated values with amplitude ratios in seismograms may provide information concerning the elastic properties at the boundary between core and mantle, and that it may aid the investigation of the problem of whether the earth's core, though not necessarily a fluid, resembles a fluid in not transmitting shear waves.

An important application of these calculations is in interpreting points on seismograms where confusion is caused by almost simultaneous arrival of various waves. Thus, also, will discrimination be facilitated between branches of phases which follow each other at short intervals but with different amplitudes.

Finally, the fact that absorption was neglected in these calculations indicates yet another application for them. The comparison of the ratios of the horizontal and vertical components of the ground displacement produced by a certain seismic wave (as calculated in this paper). with actual amplitude ratios taken from seismograms for that particular wave should give the relative absorption that has taken place in its path.

\section{ACKNOWLEDGMENT}

The author is greatly indebted to Dr. Beno Gutenberg for his constant supervision and constructive criticism in preparing this article and the previous paper.

California Institute of Technology

Pasadena, CaLifornia

. Balch Graduate Schiool of the Geological Sciences, Contribution No. 374) 